\title{
Superior Parietal Convolution
}

National Cancer Institute

\section{Source}

National Cancer Institute. Superior Parietal Convolution. NCI Thesaurus. Code C33692.

A gyrus or ridge in the parietal lobe surrounded by the post-central sulcus, external parieto-occipital fissure, horizontal section of the intra-parietal sulcus and the inner surface of the quadrate lobe. 